\title{
Analysis of the Palliative Care Need for the Population of the Precarpathion Region (Letter)
}

\author{
I. Slugotska (Iryna Slugotska), J. Zolotareva (Jhanna Zolotareva), A. Wolf \\ (Alexander Wolf)
}

Ivano-Frankivsk Regional Clinical Center for Palliative Care, UA

Original Article

Ivano-Frankivsk National Medical University, UA

\section{E-mail address:}

slugotska@ukr.net

\section{Reprint address:}

Iryna Slugotska

Regional Clinical Palliative Care Centre

Novakivskogo str. 8

76018, Ivano-Frankivsk

UA

Suource: Clinical Social Work and Health Intervention

Pages: $86-88$

Volume: 8

Issue: 4

\section{Reviewers:}

Pawel S. Czarnecki

Rector of the Warsaw Management University, PL

Andrea Shahum

University of North Carolina at Chapel Hill School of Medicine, USA

\section{Key words:}

Need for Palliative Care. Trends of Morbidity and Mortality. Planning. Different Types of Settings and Forms.

\section{Publisher:}

International Society of Applied Preventive Medicine i-gap

CSWHI 2017; 8(4): 86 - 88; DOI 10.22359/cswhi_8_4_11 @ 2017 Clinical Social Work and Health Intervention

\section{Abstract:}

Objective: The need for palliative care around the world will increase at least three times by 2040 . So, it is crucial to predict which forms of palliative caregiving will be needed; how will this need grow in the next 3-5 years. That was our task. 
Methods: Analysis of statistical reporting data for the last 5 years (Precarpathion Region).

Results: We have rationed the acute need of residents of the city and region in expanding the availability of palliative care for patients with chronic incurable diseases; especially at home; a visiting mobile team; the need to establish nursing homes care; with various forms of palliative caregiving and education for these.

\section{Background}

The aim of the study. Within the framework of the last XVI EAPC Congress (Madrid, May 18-20, 2017), the need for palliative care around the world will increase at least three times by 2040. Therefore, assessing and analyzing such a need in our region is an urgent task for planning the proportion of different types of settings, such assistance, necessary human resources and facilities [1].

It is crucial to predict which forms of palliative care giving will be needed; which of them will be the most comfortable for the patient; will provide him and his family members with quality and affordable palliative care from the moment of diagnosis of incurable illness until the end of life in any place where the palliative patient is located [1]. And how will this need grow in the next 3-5 years. That was our task.

\section{Research methods}

Analysis of statistical reporting data for the last 5 years (statistical materials of the Regional Information-analytical Center of Medical Statistics for 2012-2016 years) where do the residents of the Region die and why do they pass away by? Analysis of the data of the population survey of Ivano-Frankivsk and the Region concerning palliative care.

\section{Main results}

We performed an analysis of the 5-year trends in mortality and morbidity for the Precarpathion population in order to understand the changes in the number and causes of deaths in our Region. Attention was focused on the adult population (as an object of research), because there are more definite age and nosological groups.

The main trends of morbidity and mortality in the three most important nosological groups were analyzed, namely: cardiovascular, oncological and cerebrovascular diseases. The most significant was the increase in the morbidity of cancer (from 2,050.6 to 2,218.7 per 100 thousand us.) [2]. This also indicates an improvement in diagnostics.

In terms of mortality rates, a clear increase was observed in the cardiovascular groups (from 441, 89 to 493.71 per 100 thousand) and cerebrovascular (from 56.07 to 60.31 per 100 thousand), but non-cancerous diseases (in this group, mortality even decreased from 179.10 to 168.86 per 100 thousand us) [2].

In parallel, a survey was conducted among the inhabitants of Precarpathion Region (969 people were interviewed). It has been established that $72.4 \%$ of residents do not know at all what such palliative care is and where it is provided. $80.6 \%$ of the residents of Region indicated that in the event of a severe incurable illness, they would like to pass away complete at home, but with the help of doctors of the mobile specialized hospice team. 
$86.2 \%$ of residents who care for palliative relatives at home need help of the mobile specialized hospice team.

$30.4 \%$ of such caregivers for seriously ill relatives would like and need a transfer of such a patient to a hospital (hospice).

\section{Conclusions}

Detected trends of mortality and morbidity show:

1. The acute need of residents of the city and Region in expanding the availability of palliative care for patients with chronic incurable diseases, especially at home, visiting mobile team;

2. The need to establish nursing homes care, both in Ivano-Frankivsk and in future hospital districts;
3. The creating of mobile palliative teams in Precarpathion Region.

It is also important to expand the informing of the Precarpathion community about the possibility of providing such care and various forms of its provision.

\section{References}

1. CALANZANI N, HIGGINSON I J, GOMES B (2013) Current and future needs for hospice care: an evidence-based report. Commission into the Future of Hospice care, Hospice house, 34-44 Brittania St. London WC1X9JG, January, 2013; P. 8-9.

2. OFFICE FOR NATIONAL STATISTICS. Mortality statistics: Deaths registered in 2014-2016. Data directory for national Statistic (Precarpathian region), part 1, 2016. 